\title{
Assessment and Risk Management in the Laboratories of the School of Public Health, a Medical University Using the ACHiL Technique
}

\author{
Iraj Mohammadfam ${ }^{1,}$, Farshad Abdollahi' ${ }^{2}$, Safoura Karimi ${ }^{3}$
}

${ }^{1}$ Professor, Scientific Center of Excellence for Occupational Health, Occupational Health and Safety Research Center, Department of Occupational Health, Faculty of Health, Hamadan University of Medical Sciences, Hamadan, Iran

${ }^{2}$ BSc in Occupational Health Engineering, Scientific Center of Excellence for Occupational Health, Occupational Health and Safety Research Center, Department of Occupational Health, Faculty of Health, Hamadan University of Medical Sciences, Hamadan, Iran

${ }^{3}$ MSc in Occupational Health Engineering, Scientific Center of Excellence for Occupational Health, Occupational Health and Safety Research Center, Department of Occupational Health, Faculty of Health, Hamadan University of Medical Sciences, Hamadan, Iran

* Corresponding Author: Iraj Mohammadfam, Center of Excellence for Occupational Health, Occupational Health and Safety Research Center, Department of Occupational Health Engineering, School of Public Health, Hamadan University of Medical Sciences, Hamadan, Iran.Email: mohammadfam@umsha.ac.ir

Received: $13 / 07 / 2018$

Accepted: 21/09/2018

How to Cite this Article: Mohammadfam I, Abdollahi F, Karimi S. Assessment and Risk Management in the Laboratories of the School of Public Health, a Medical University Using the ACHiL Technique. $J$ Occup Hyg Eng. 2018; 5(2): 20-27. DOI: 10.21859/johe.5.2.20

\section{Abstract}

Background and Objective: Despite continuous efforts to reduce risks in different systems, unsafe mistakes and behaviors are the main causes of incidents at the workplace. The safety of laboratories is important because of the variety of chemicals, electrical equipment, high costs of some pieces of equipment, as well as the large number of students, professors, and staff who use labs. For this reason, it is necessary to identify, assess, and control their hazards by appropriate methods.

Materials and Methods: In this study, the assessment and classification of hazards in laboratories (ACHiL) method was used. The ACHiL approach was based on a platform in which 28 risks were classified into three levels based on their limitations. Limit values were edited by United Nations Organization, The International Agency for Research on Cancer, and other global requirements.

Results: The results of this study showed that chemical agents were identified as the most important risk factor in the studied laboratories. Environmental agents were also identified as the second most effective factor in the occurrence of accidents. Biological agents and then physical agents had the least important roles in the occurrence of accidents in the studied laboratories. Furthermore, the level and the location of hazards were defined based on their severity.

Conclusion: The ACHiL platform is a simple yet highly efficient tool for health and safety professionals. This allows them to get a full and deep view of the existing hazards, as well as dangerous samples in the lab in order to take appropriate safety measures.

Keywords: ACHiL Technique; Laboratory; Risk 


\section{ارزيابى و مديريت ريسك در آزمايشكاههاى دانشكده بهداشت يكى از دانشكاههاى علوم ACHiL يزشكى با استفاده از تكنيك}

ايرج محمدفام ا“*، فرشاد عبدالهى '، صفورا كريمى

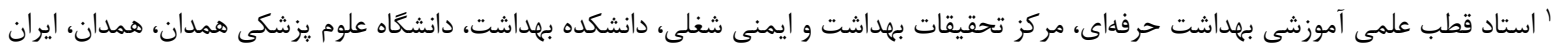

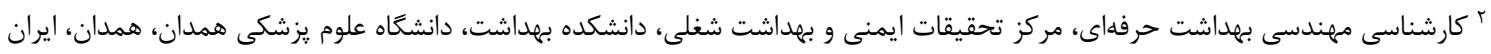

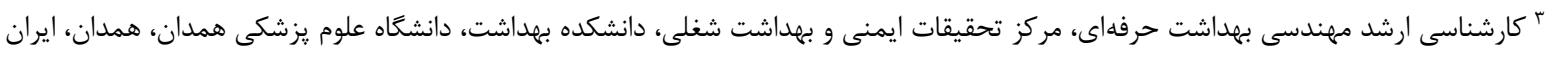
* ن نويسنده مسئول: ايرج محمدفام، مركز تحقيقات بهداشت و ايمنى شغلى، دانشكده بهداشت، دانشكاه علوم يزشكى همدان، همدان، ايران. ايميل: mohammadfam@umsha.ac.ir

\section{جكيده}

سابقه و هدف: با وجود تلاشهاى مداوم براى كاهش ريسك در سيستمهاى مختلف، هنوز هم حوادث رخ

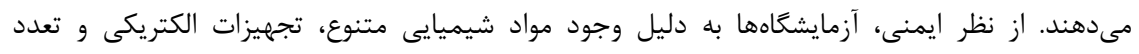

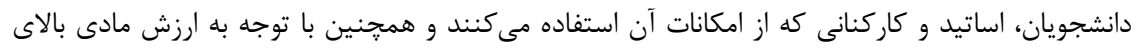

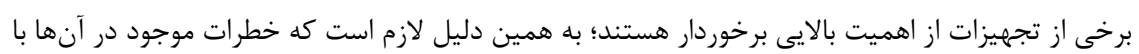
استفاده از روشهاى مناسب شناسايى، ارزيابى و كنترل كردند.

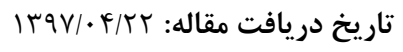

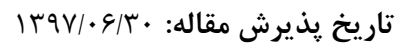
تمامى حقوق نشر براى دانشكاه علوم يزشكى همدان محفوظ است.

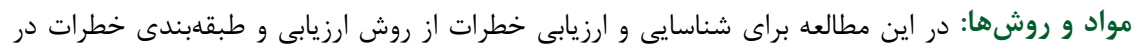

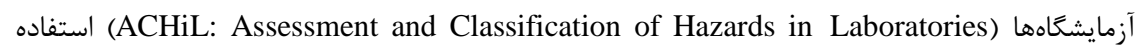
كرديد. روش ACHiL بر مبناى ساختارى طراحى شده است كه م خ خطر در آن دستهبندى شده است كه

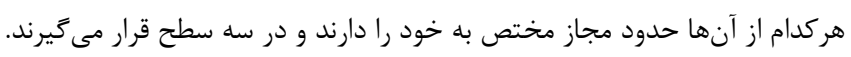

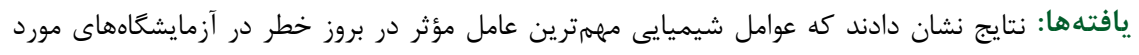

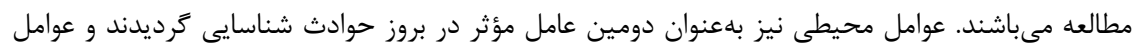

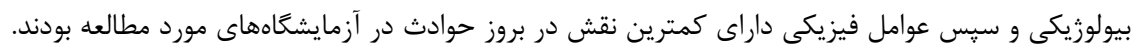

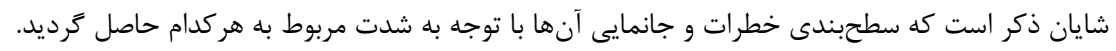

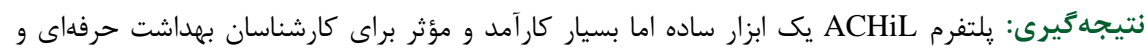

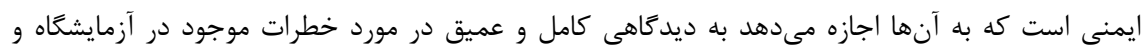

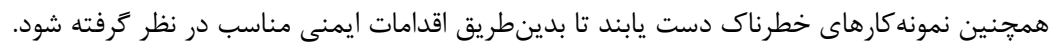

وازَّان كليدى: آزمايشعاه، تكنيك ACHiL، ريسك

از: دولت، مراقبتهاى بهداشتى، آموزش و اوقات فراغت كه انتظار

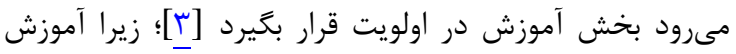

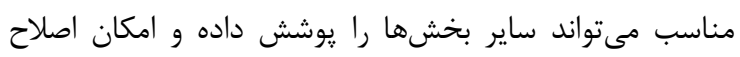

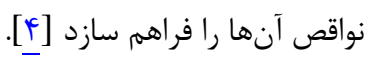

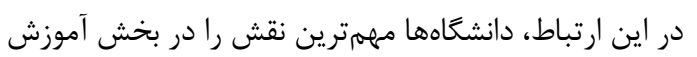

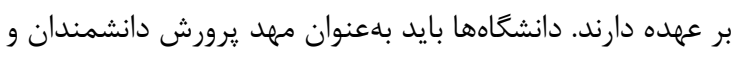
يروهشكران، محيط كار سالم و ايمنى را براى اساتيد، دانشجويان

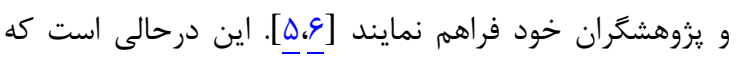

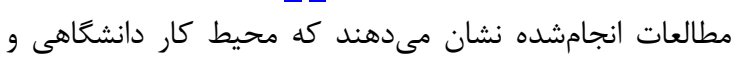

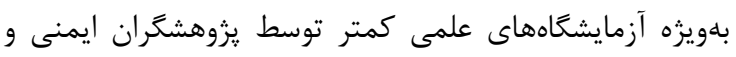

مقدمه

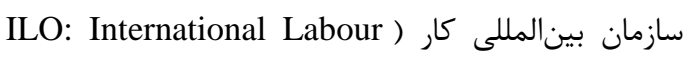

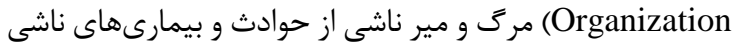

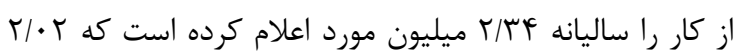

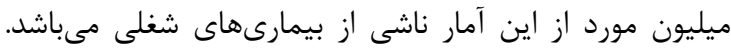

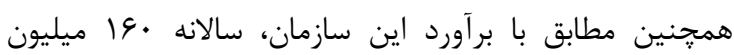

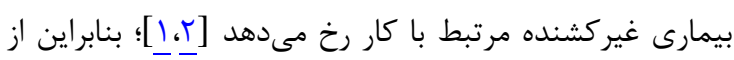

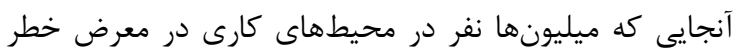

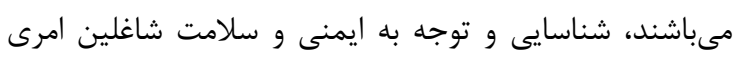
ضرورى است. جهار اصل يیشرفت يك كشور در قرن بيستم عبارت هستند 
جراحت جندين نفر رادر يى داشت [ب]].

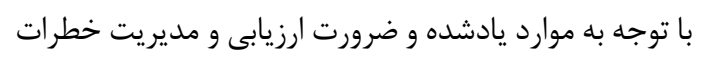

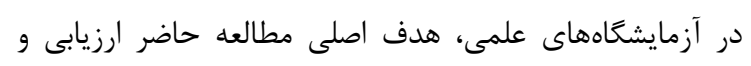

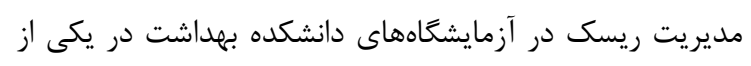

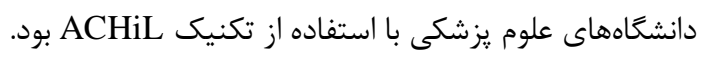

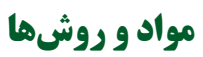

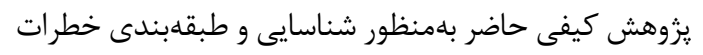

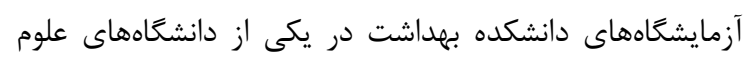

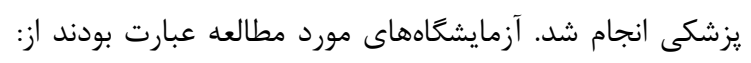

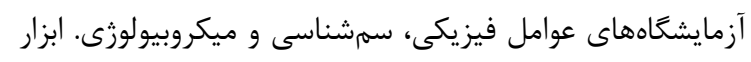

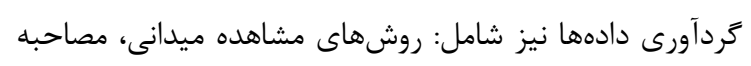

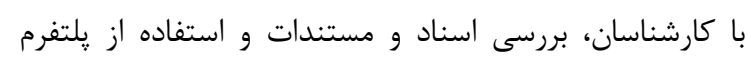

شناسايى خطرات موجود تكنيك ACHiL بود [IV]

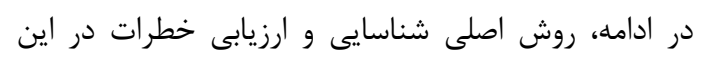

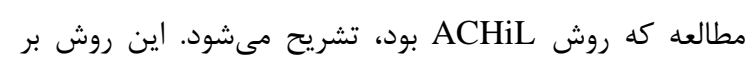

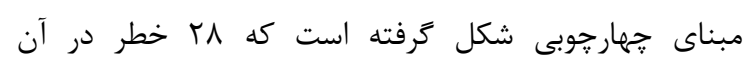

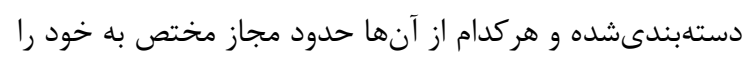

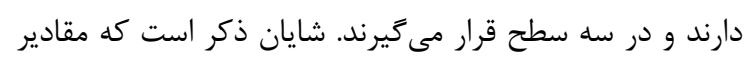

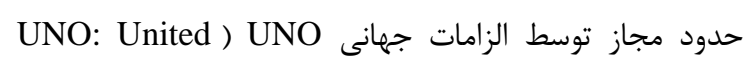
IARC: International ) IARC ،Nations Organization (Agency for Research on Cancer

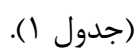

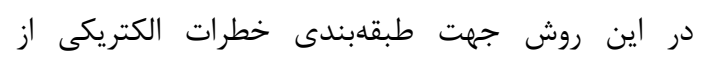

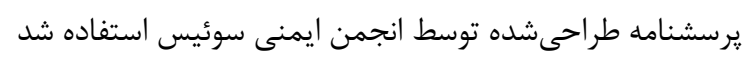

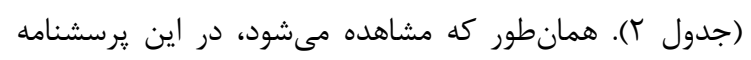

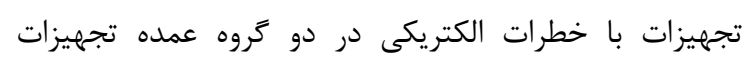

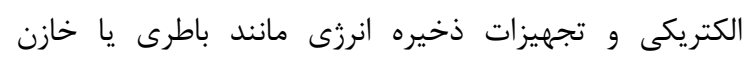
طبقابندى شدهاند.

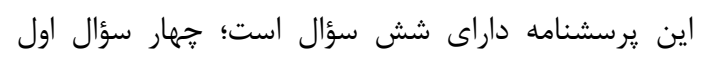

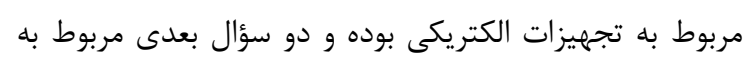

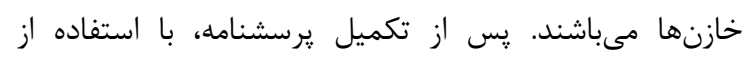

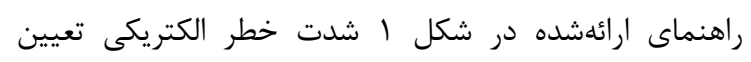

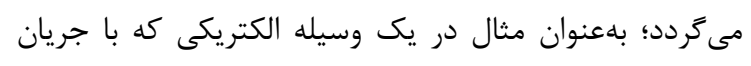

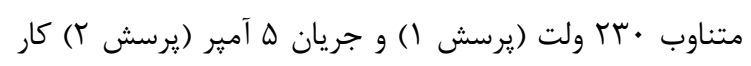

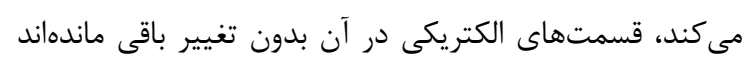

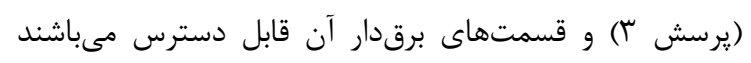

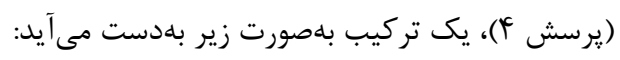

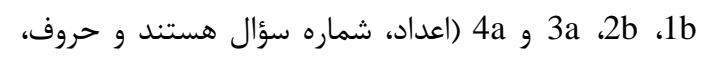

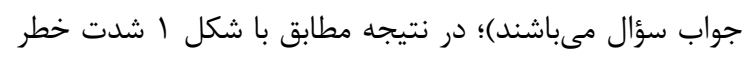
اين دستخاه إمى مباشد.

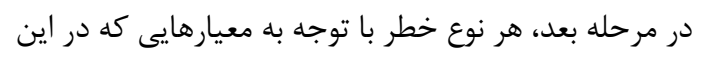

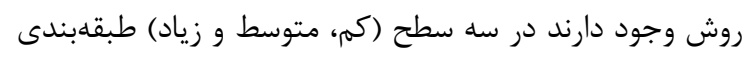

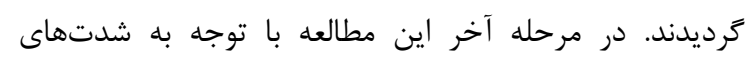

بهداشت مورد بررسى و ارزيابى قرار كرفتهاند. فعاليتهاى

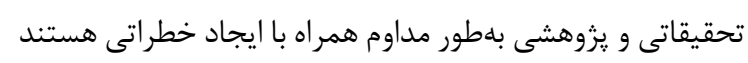

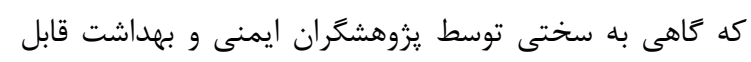

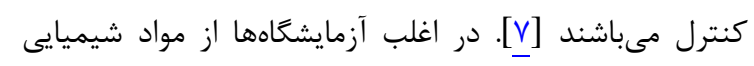

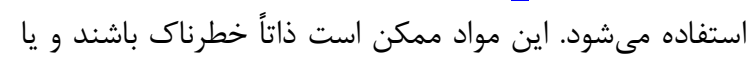

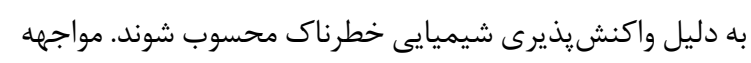

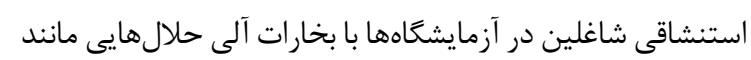

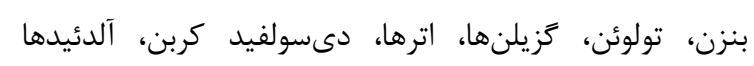

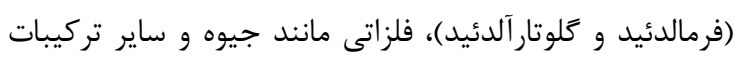

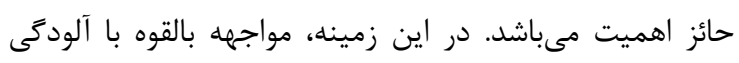

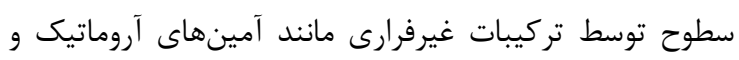

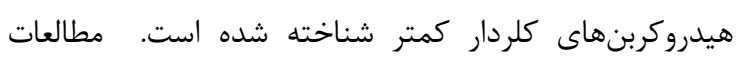

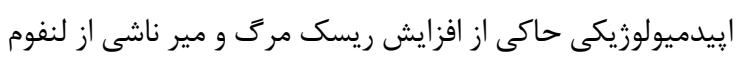

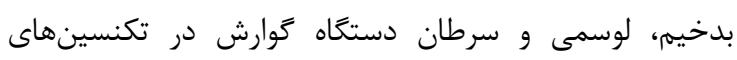

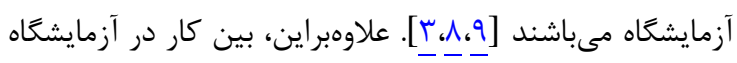

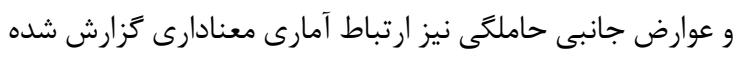

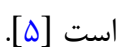

وجود سليندرهاى تحت فشار حاوى كازهاى سمى، قابل

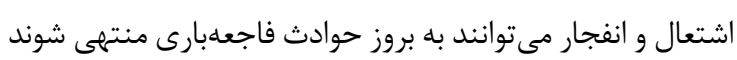

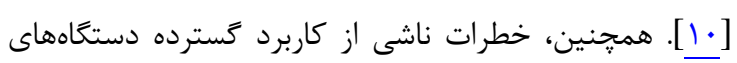

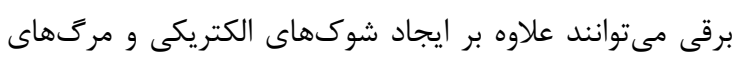

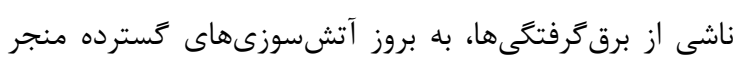

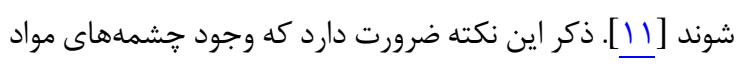

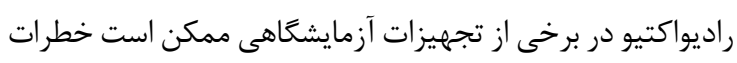

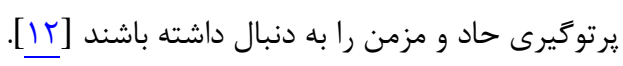

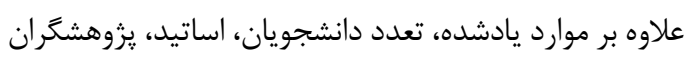

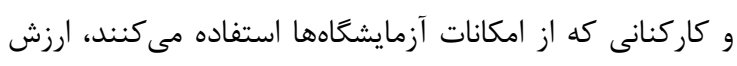

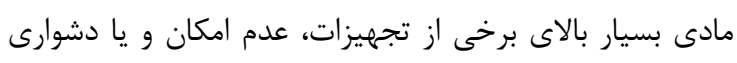

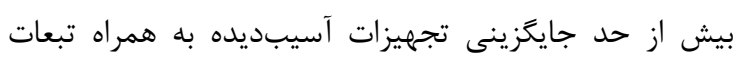

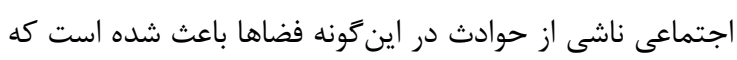

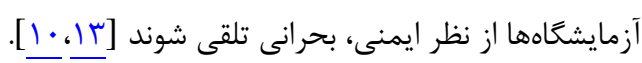

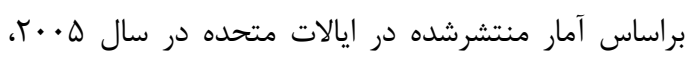

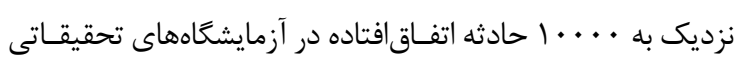

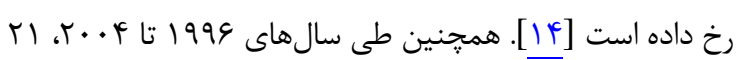

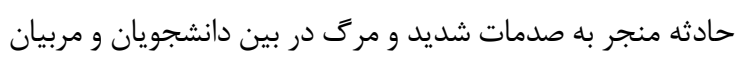

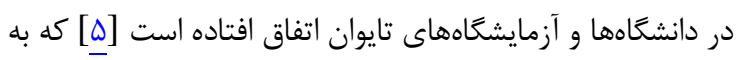

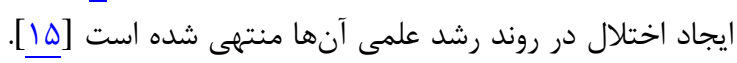

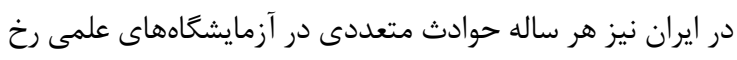

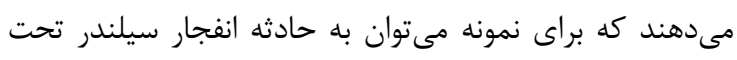

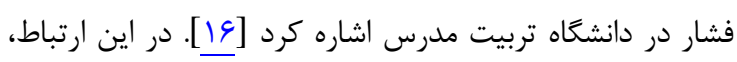

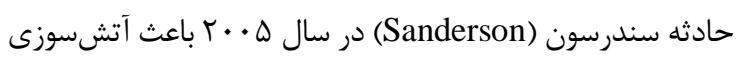

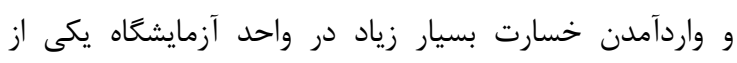
دانشكاههاى انعَلستان شد. حادثه فريمنتال (Freemental) نيز

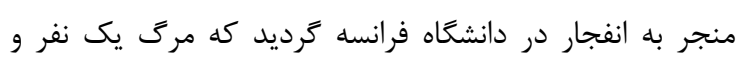


جدول ا: خطرات موجود در يلتفرم ACHiL

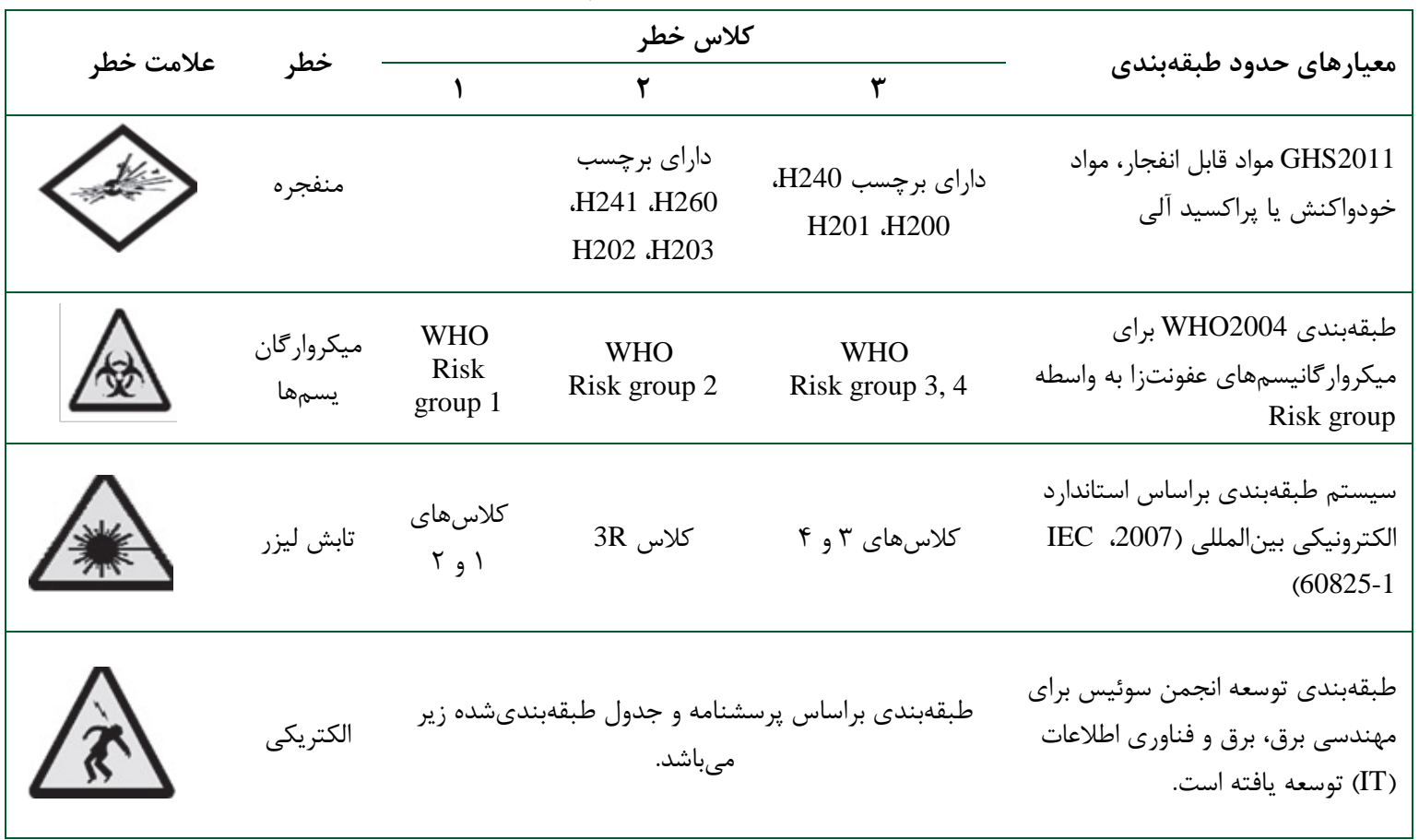

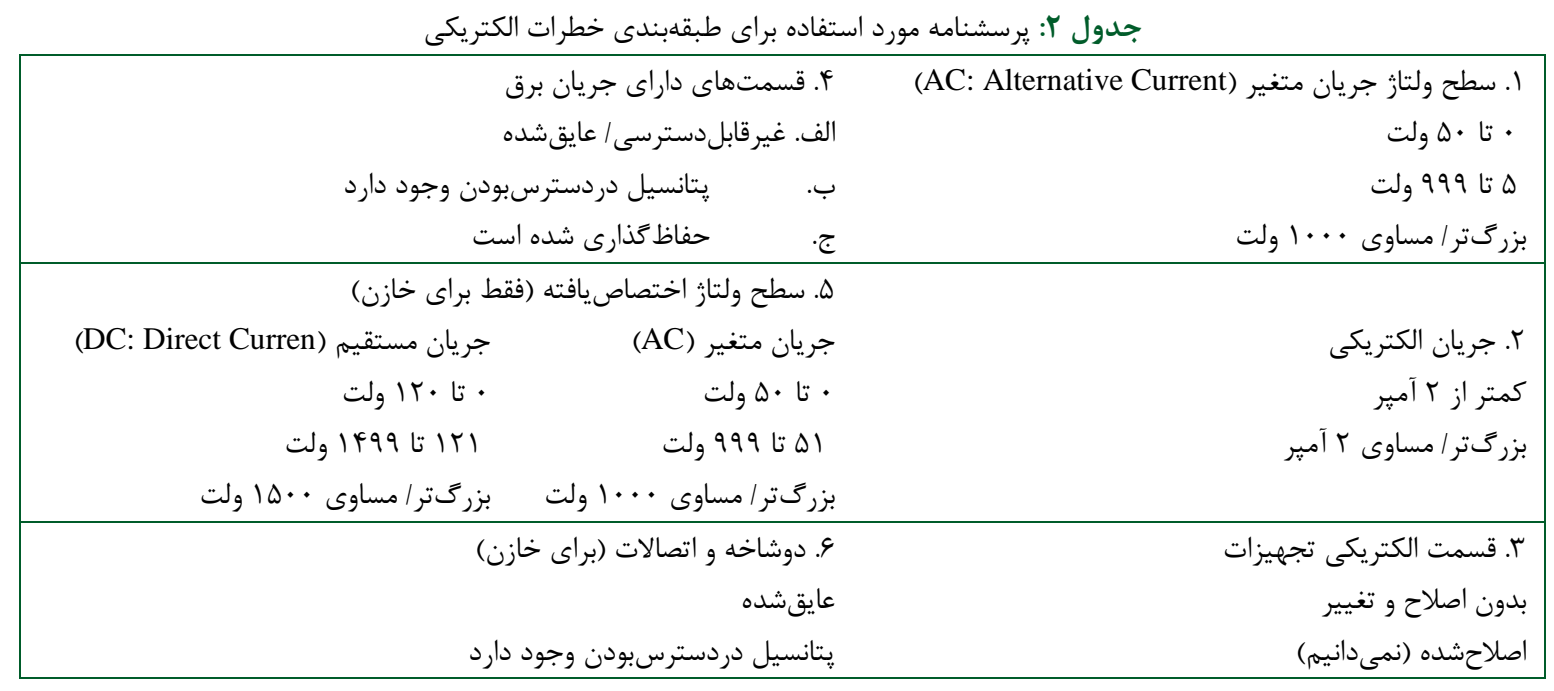

Equipment without capacitor

\begin{tabular}{|c|c|c|c|c|}
\hline $1 a$ & \multicolumn{5}{|c|}{0} \\
\hline $2 a$ & \multicolumn{5}{|c|}{} \\
\hline \multirow{2}{*}{$2 b$} & $3 a$ & 1 & 2 & 1 \\
\cline { 2 - 5 } & $3 b$ & 1 & 2 & 2 \\
\hline \multicolumn{1}{|c}{} & $4 a$ & $4 b$ & $4 c$ \\
\cline { 4 - 5 } & &
\end{tabular}

\begin{tabular}{|c|c|c|c|c|}
\hline $1 \mathrm{~b}$ & \multicolumn{4}{|c|}{ Pos. 2 not relevant } \\
\hline & $3 a$ & 1 & 3 & 1 \\
\cline { 2 - 5 } & $3 \mathrm{~b}$ & 2 & 3 & 2 \\
\hline
\end{tabular}

\begin{tabular}{|c|c|c|c|c|}
\hline 1c & \multicolumn{4}{|c|}{ Pos. 2 not relevant } \\
\hline & $3 a$ & 1 & 3 & 2 \\
\cline { 2 - 5 } & $3 b$ & 2 & 3 & 2 \\
\hline
\end{tabular}

شكل ا: طبقلبندى خطرات الكتريكى براساس سؤالات پاسخدادهده در پرسشنامه

\section{Capacitor}

\begin{tabular}{|c|c|}
\hline $5 a$ & \\
\hline $6 a$ & 0 \\
\hline $6 b$ & 1 \\
\hline
\end{tabular}

\begin{tabular}{|l|l|}
\hline $5 b$ & \\
\hline $6 a$ & 1 \\
\hline $6 b$ & 2 \\
\hline
\end{tabular}

\begin{tabular}{|l|l|}
\hline $5 c$ & \\
\hline $6 a$ & 2 \\
\hline $6 b$ & 3 \\
\hline
\end{tabular}


بكرل يرتو نيز در حد متوسط (Medium) ارزيابى شد (جدول r

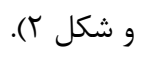

آزمايشكاه ميكروبيولوزى

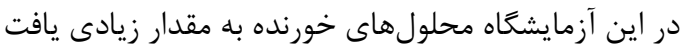

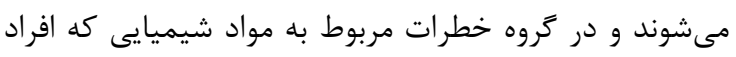

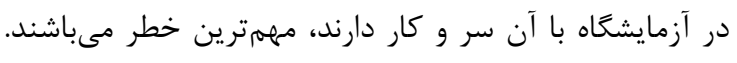
در يزوهش حاضر شدت خطر مواد خورنده در آزمايشعاه

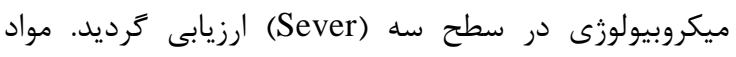
مصرفى ديگر كه خطرناك هستند (مانند اكسيدكنندهها و ورئو محلولهايى كه خطرات زيست محيطى دارند)، داراى شدرت

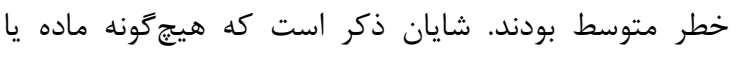

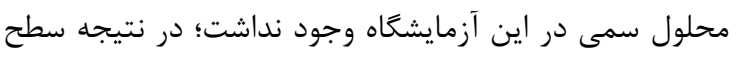

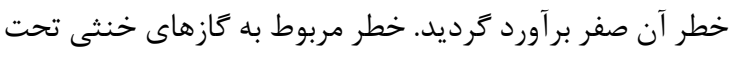

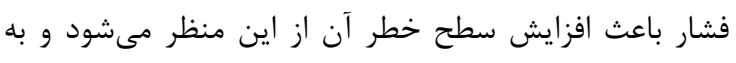

\begin{tabular}{|c|c|}
\hline شدت خطر & نوع خطرات \\
\hline متوسط & محلول قابل اشتعال \\
\hline زياد - اد & مواد سمى \\
\hline متوسط & خطرات محيطى \\
\hline 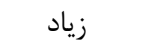 & مواد خورنده \\
\hline 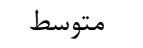 & خطرات الكتريكى \\
\hline 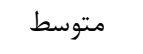 & يرتو يونيزان \\
\hline متوسط & محرك سيستم تنفسى \\
\hline زياد - اد & كاز خنثى - تحت فشار \\
\hline زياد & كاز قابل اشتعال- تحت فشار \\
\hline
\end{tabular}

بلدستآمده، خطرات موجود در نقشه آزمايشخاههاى مورد مطالعه جانمايى شدند.

\section{بافتهها}

در ادامه، نتايج براساس آزمايشگاه مورد بررسى ارائه مىشوند.

$$
\text { آزمايشكاه سمرشناسى }
$$

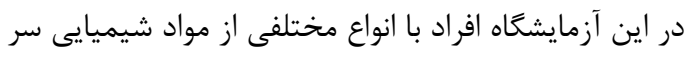

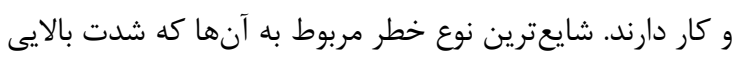

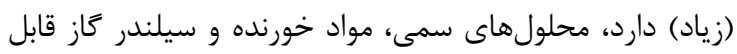

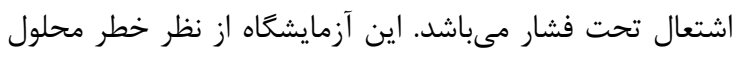

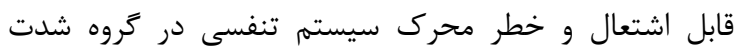
متوسط (Medium) قرار مى گيرد. بايد عنوان نمود كه خطر مواد

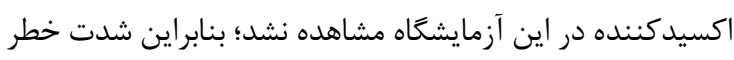

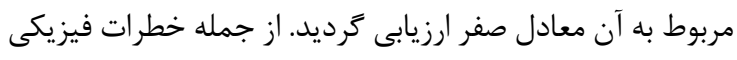

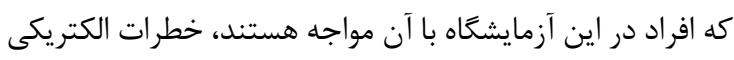

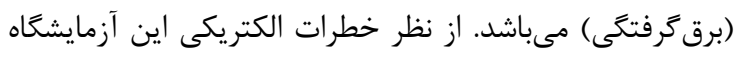

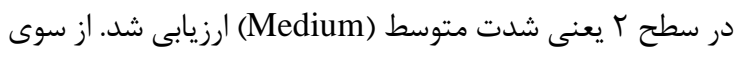

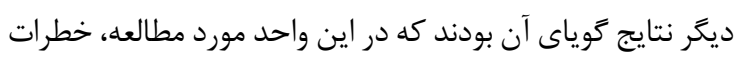
مربوط به يرتوهاى يونيزان و غيريونيزان بسيار محدود هستند دئن

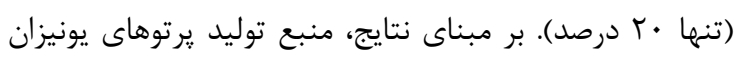

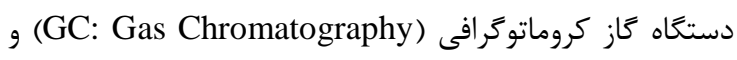

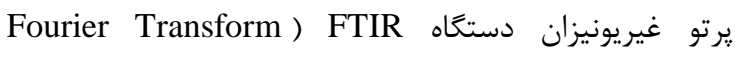
(Infrared Spectroscopy يرتوهاى يادشده كاملاً محصور شده است، شدت آن بسيار يايين

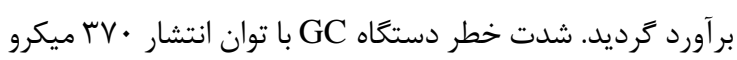
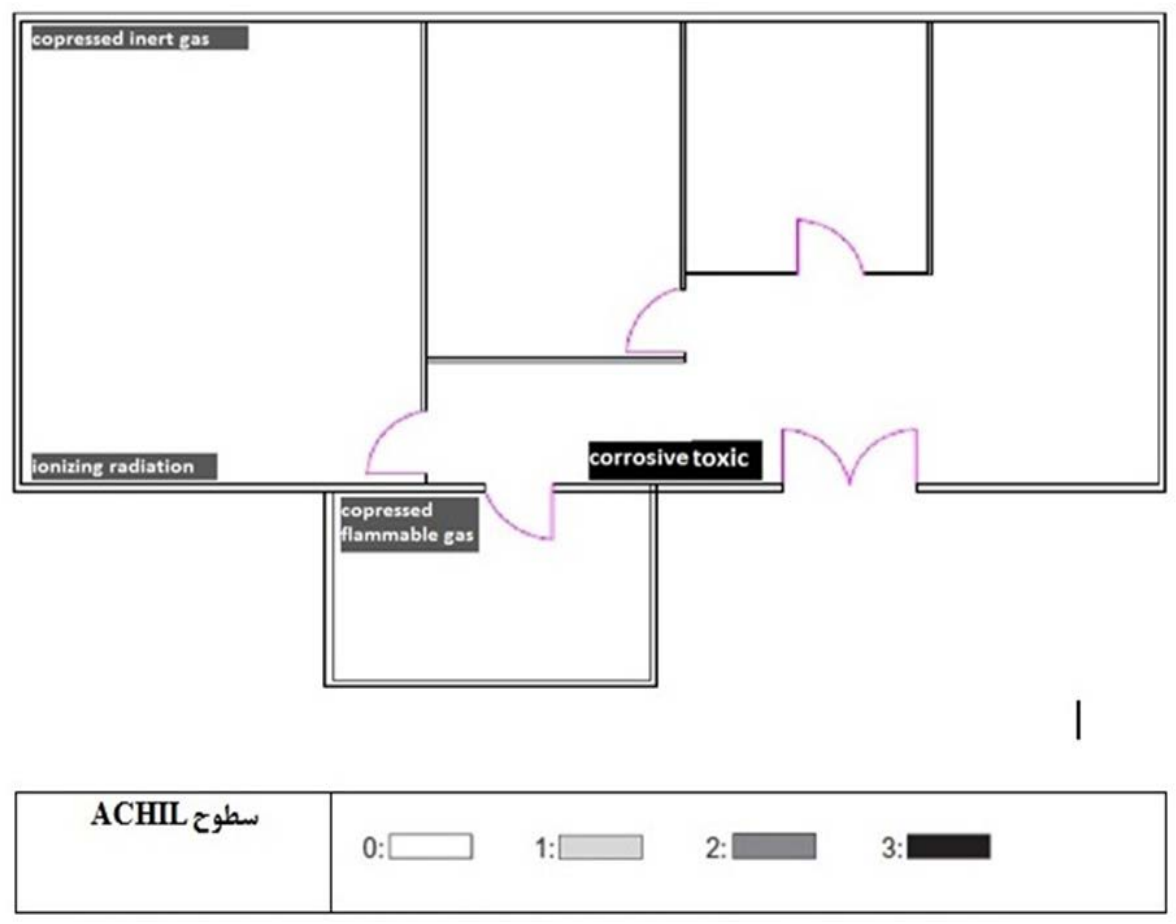

شكل r: جانمايى خطرات برجسته در آزمايشگاه سمشناسى 


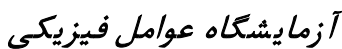

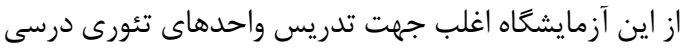

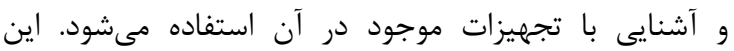

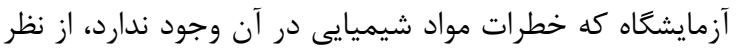

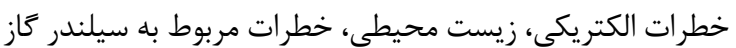
تحت فشار و يرتوها ايمن ارزيابى كرديد.

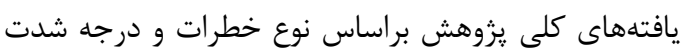

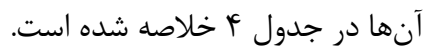

همين دليل شدت اين خطر در اين آزمايشكاه معادل r (Sever)

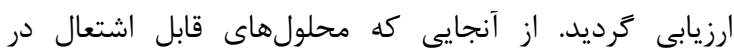

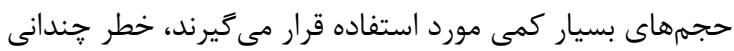
افراد را تهديد نمى كند؛ زيرا شدت آنهائ آنها بإيين (Moderate)

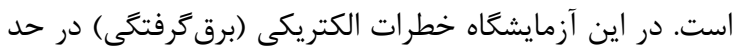

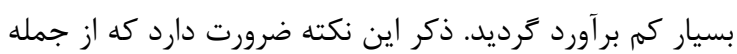

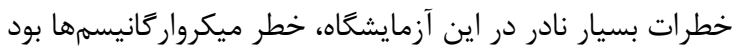
كه شدت خطر آنها متوسط كزارش شد.

جدول F: خطرات موجود در آزمايشعاهها مطابق با ساختار روش ACHiL

\begin{tabular}{|c|c|c|c|c|}
\hline \multirow{2}{*}{ كل } & \multicolumn{3}{|c|}{ شدت } & \multirow{2}{*}{ خطرات } \\
\hline & زياد & متوسط & كم & \\
\hline r & 1 & 1 & $r$ & محلول قابل اشتعال \\
\hline r & r & 1 & $\cdot$ & ماده سمى \\
\hline r & 1 & 1 & $r$ & خطرات محيطى \\
\hline r & r & . & . & خورنده \\
\hline$r$ & 1 & r & $\cdot$ & اكسيدكننده \\
\hline r & . & r & 1 & خطرات الكتر يكى \\
\hline 1 & $\cdot$ & 1 & $\cdot$ & يرتو يونيزان \\
\hline r & · & r & $\cdot$ & محرك سيستم تنفسى \\
\hline 1 & $\cdot$ & $\cdot$ & 1 & 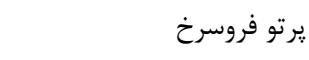 \\
\hline 1 & · & 1 & $\cdot$ & ميكرواركانيسم \\
\hline r & r & 1 & $\cdot$ & كاز خنثى - تحت فشار \\
\hline r & r & . & . & كَاز قابل اشتعال- تحت فشار \\
\hline
\end{tabular}

كزارشهاى مربوط به حوادث شيميايى در آزمايشكاههاى

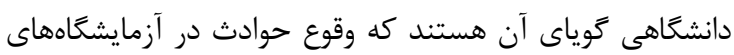

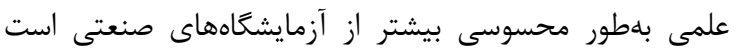

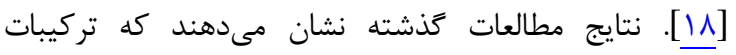

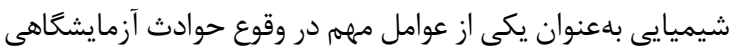

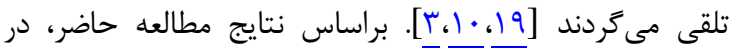

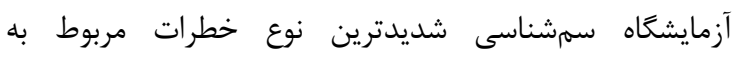

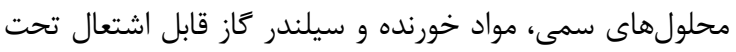
فشار بود. همجنين محلولهاى هواى خورنده و كازهاز

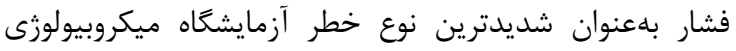

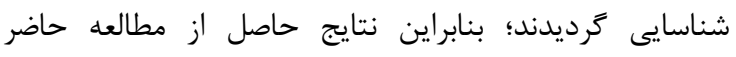

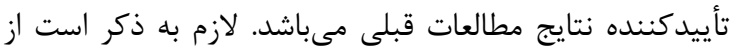

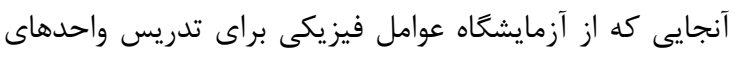
تئورى درسى و آشنايى با تجهيزات موجود در در آن آن استفاده

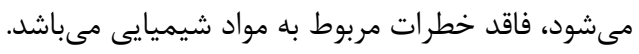

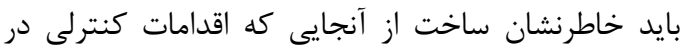

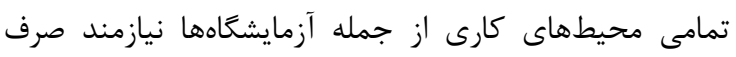

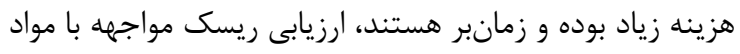

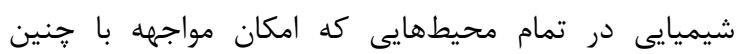

هر جند كه در ظاهر امر محيط كار آزمايشعاههاى علمى ايمن

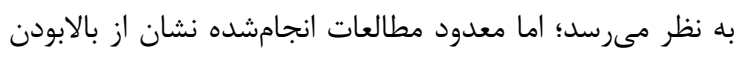

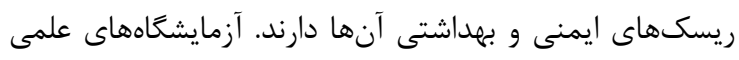

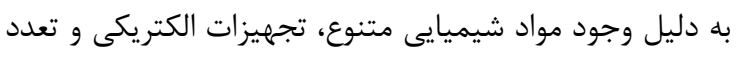

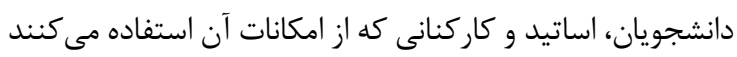

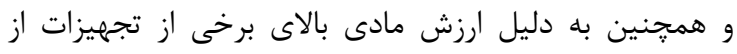

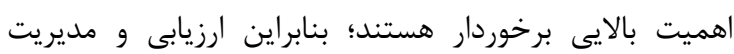

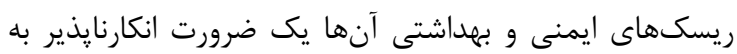

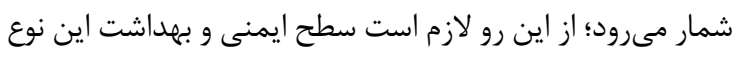

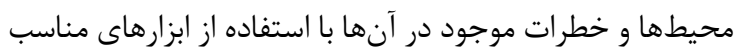

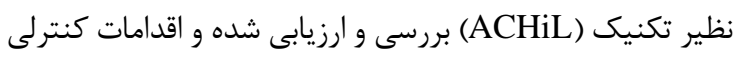
مناسب طراحى و يِادهسازى كردند.

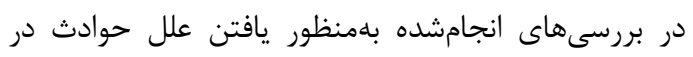

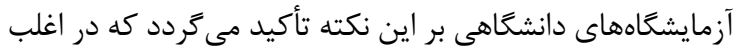

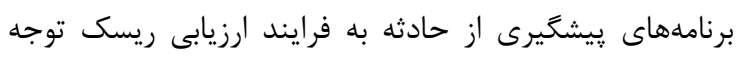

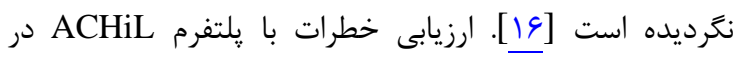

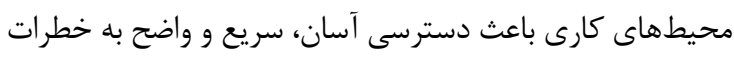

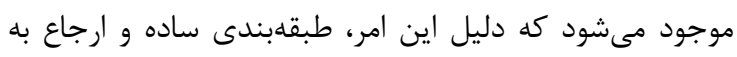

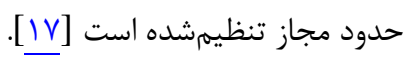


برخوردار مىباشد.

يكى از مزاياى تكنيك ACHiL نشاندادن خطراتد سطح شدت آنها در قالب يك نقشه از محيط آزمايشگاه مورد

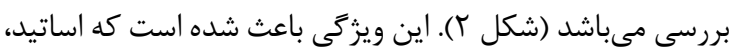

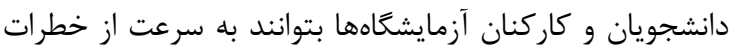

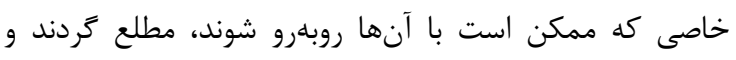

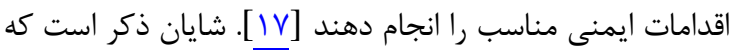

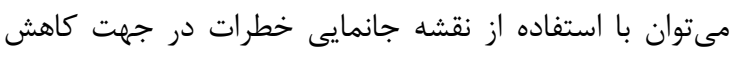
مخاطرات محيطى و ايمنكردن محيطهاى كار آزمايشگاهى جانى

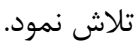
به نظر مىرسد كه تدوين خطمشى و برنامههاى مديريت

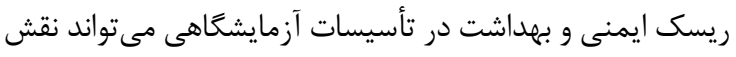

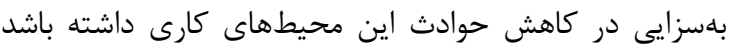

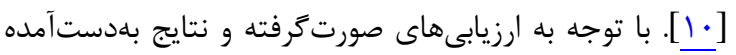

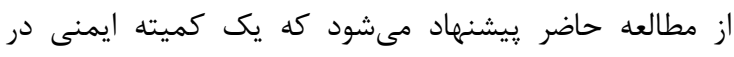

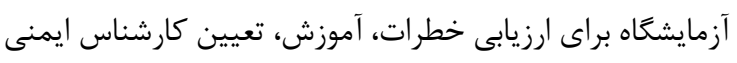

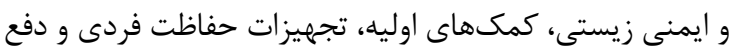
يسماندهاى خطرناك تشكيل شود.

\section{نتيجه}

يلتفرم ACHiL يك ابزار ساده اما بسيار كارآمد و مؤثر براى كارشناسان بهداشت حرفهاى و ايمنى است كه به آنها

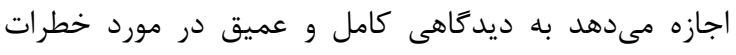

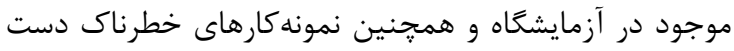

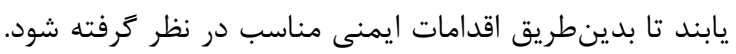
نتايج مطالعه حاضر نشان دادند كه آزمايشكاه سمشناسئى

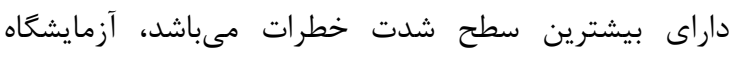
ميكروبيولوزى سطح شدت خطر كمترى نسبت به به آزمايشكاه

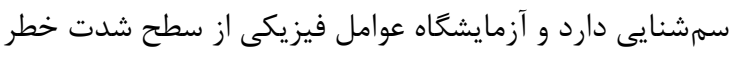

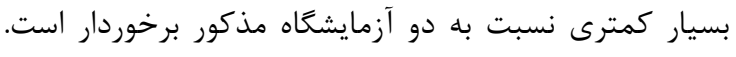

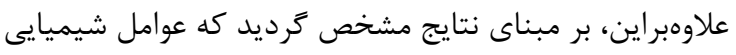

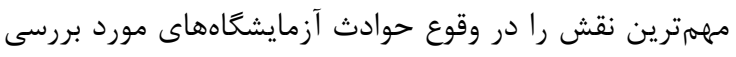

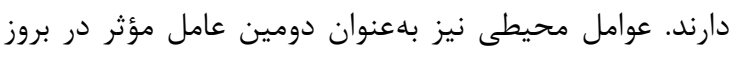

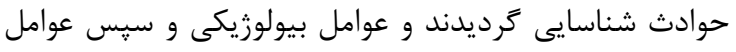
فيزيكى كمترين نقش را در بروز حوادث آزمايشعاههاى مورد

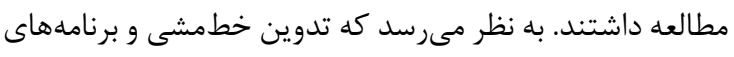

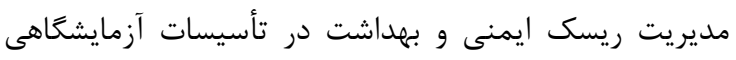
مىتواند نقش بلسزايى در كاهش حوادث اين محيطهاى كارى داشته باشد.

\section{تشكر و قدردانى}

مطالعه حاضر از سوى حوزه معاونت يزوهشى دانشعاه علوم

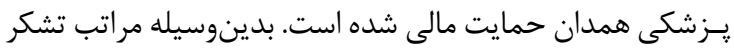
و قدردانى نسبت به اين معاونت محترم ابراز مى كردد.
آلايندهايى در آنها وجود دارد، بلمنظور اولويتبندى اقدامات

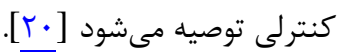
تكنيك ACHiL نوع خطرات موجود در محيط كار مورد

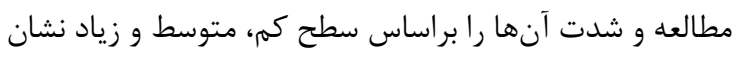

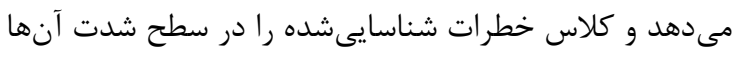
ارزيابى مى كند. [IV] مىشود، بيشترين مجموع سطح شدت خطرات مربوط به

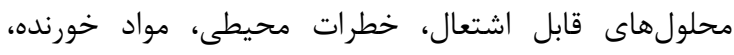

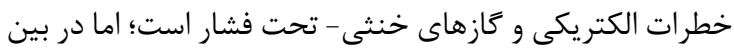

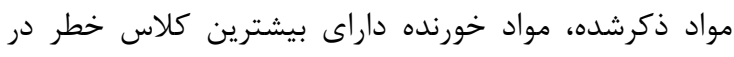

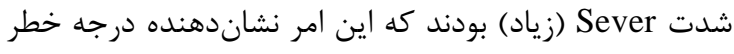

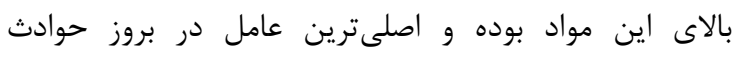

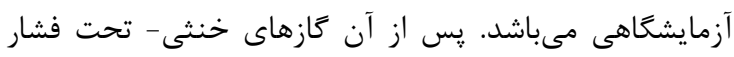

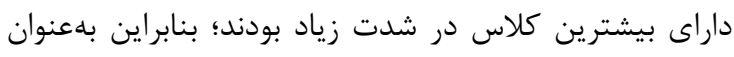

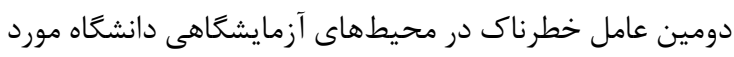

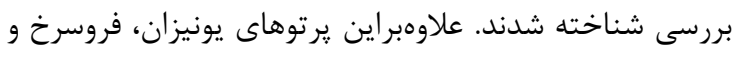

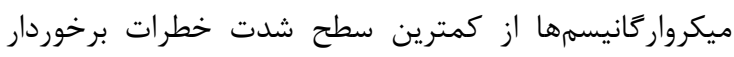

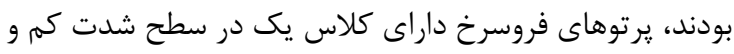

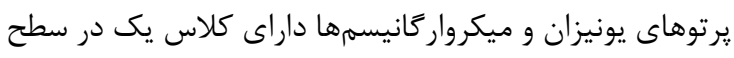

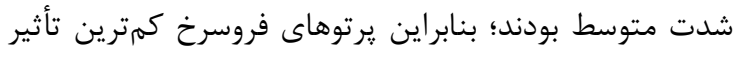

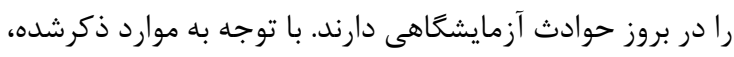

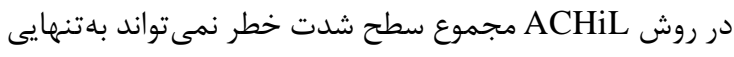

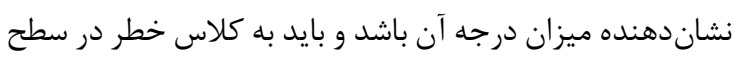
شدت هر خطر توجه گردد. همانطور كه نتايج نشان مى مدهند، مخدد مخاطرات شيميايى

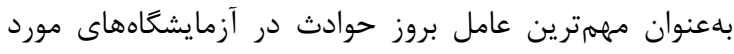

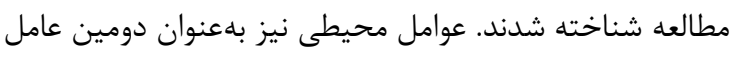
مؤثر در بروز حوادث شناسايى گرديدند. اين عوامل مى توانند شامل: جانمايى مناسب مواد موجود در آزمايشگاه، يوسترهاى برى

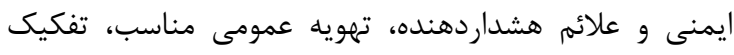

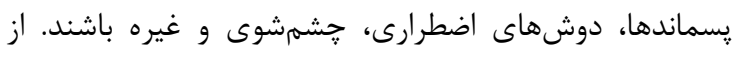

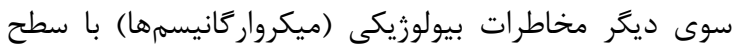

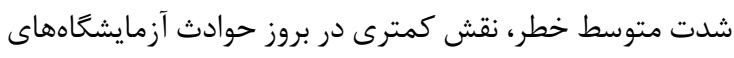

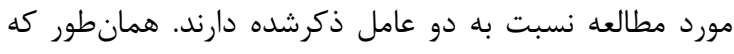

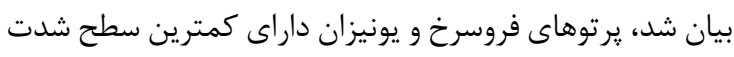

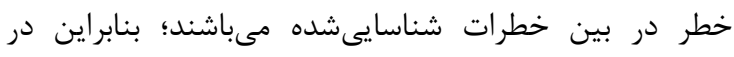

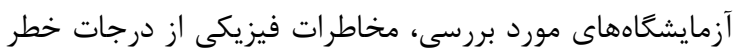

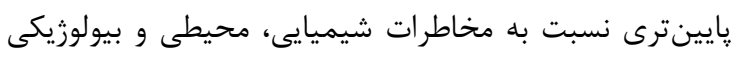
برخوردار هستند. با توجه به نتايج حاصل از مطالعه حاضر مى متوان كَفت كه

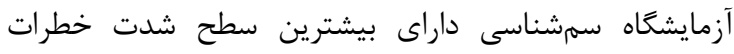

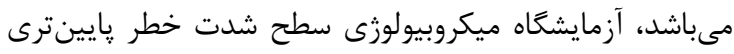

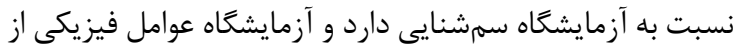
سطح شدت خطر بسيار كمترى نسبت به دو آزمايشگاه مذكور 


\section{REFERENCES}

1. Sundawa BV, Hutajulu E, Sirait R, Banurea W, Mulyadi S. Risk assessment for safety laboratories in Politeknik Negeri Medan. J Phys. 2017;890(1):12147.

2. Salguero-Caparros F, Suarez-Cebador M, Rubio-Romero JC. Analysis of investigation reports on occupational accidents. Saf Sci. 2015;72:329-36. DOI: 10.1016/j.ssci.2014.10.005

3. Malakouti J, Jang S, Mosaferchi S, Haseli F, Azizi F, Mahdinia M. Health risk assessment of occupational exposure to hazardous chemicals in laboratories of Qom University of Medical Sciences. Iran Occupat Health. 2014;11(2):13-25.

4. Soltanzadeh A, Mohammadfam I, Mahmoudi S, Savareh BA, Arani AM. Analysis and forecasting the severity of construction accidents using artificial neural network. Saf Promot Injury Prev. 2017;4(3):185-92.

5. Olin GR. The hazards of a chemical laboratory environment- study of the mortality in two cohorts of Swedish chemists. Am Ind Hyg Assoc J. 1978;39(7):557-62. PMID: 567938 DOI: $10.1080 / 0002889778507808$

6. Giroux HA. University in chains: confronting the militaryindustrial-academic complex. Abingdon: Routledge; 2015.

7. Karapantsios T, Boutskou E, Touliopoulou E, Mavros P. Evaluation of chemical laboratory safety based on student comprehension of chemicals labelling. Educ Chem Eng. 2008;3(1):66-73. DOI:10.1016/j.ece.2008.02.001

8. Hamelin EI, Blake TA, Perez JW, Crow BS, Shaner RL, Coleman RM, et al. Bridging the gap between sample collection and laboratory analysis: using dried blood spots to identify human exposure to chemical agents. Proc SPIE Int Soc Opt Eng. 2016;98630:9. PMID: 27942095 DOI: 10.1117/12.2223796

9. Vonshak A. Laboratory techniques for the cultivation of microalgae. Handbook of Microalgal Mass Culture. New Jersey: CRC Press; 2017. P. 117-46.

10. Mehrdad R, Hosseini A. Situation of safety and protection of personnel's in diagnostic laboratories in relation to radioactive Iodine. Yafte. 2007;9(1):23-8. [Persian]
11. Rasool SR, Al-Dahhan WH, Al-Zuhairi AJ, Hussein FH, Rodda KE, Yousif E. Fire and explosion hazards expected in a laboratory. J Lab Chem Educ. 2016;4(2):35-7. DOI: 10.5923/j.jlce.20160402.02

12. Kim D. Remote detection of radioactive material on the basis of the plasma breakdown using high-power millimeter-wave source. [PhD Thesis]. Ulsan, South Korea: Ulsan National Institute of Science and Technology; 2017.

13. Moskowitz PD, Fthenakis VM, Lee JC. Protecting worker health and safety in photovoltaic research and development laboratories. Solar Cells. 1989;27(1-4):149-58. DOI: 10.1016/ 0379-6787(89)90024-0

14. Wu TC. Safety leadership in the teaching laboratories of electrical and electronic engineering departments at Taiwanese Universities. J Safety Res. 2008;39(6):599-607. PMID: 19064045 DOI: 10.1016/i.jsr.2008.10.003

15. Motovagheh $M$, Jahangiri M. Health risk assessment of harmful chemicals: case study in a petrochemical industry. Iran Occupat Health. 2011;7(4):4. [Persian]

16. Dehdashti A, Hafezi R. Health, safety and environmental risk assessment in an academic laboratory: A case study. Iran Occupat Health. 2015;12(1):66-86. [Persian]

17. Marendaz JL, Suard JC, Meyer T. A systematic tool for assessment and classification of hazards in laboratories (ACHiL). Safety Sci. 2013;53:168-76. DOI: 10.1016/j. ssci.2012.10.001

18. Leggett DJ. Lab-HIRA: Hazard identification and risk analysis for the chemical research laboratory: Part 1. Preliminary hazard evaluation. J Chem Health Saf. 2012; 19(5):9-24. DOI: 10.1016/j.jchas.2012.01.012

19. Marendaz JL, Friedrich K, Meyer T. Safety management and risk assessment in chemical laboratories. CHIMIA Int J Chem. 2011;65(9):734-7. DOI: 10.2533/chimia.2011.734

20. Zeverdegani SK, Barakat S, Yazdi M. Validation CHEM-SAM model using SQRA method in exposure to toxic substances in a chemistry research lab. J Mil Med. 2017;19(3):291-8. 